\title{
Desain Sistem Informasi Persediaan Barang di Balai Latihan Kerja, Kota Salatiga dengan Framework Bootstrap
}

\author{
Nadila Agustina, Evi Maria*, Christ Rudianto \\ Fakultas Teknologi Informasi, Universitas Kristen Satya Wacana, Salatiga, Indonesia \\ Email: ${ }^{1552018002 @ s t u d e n t . u k s w . e d u, ~ 2, * e v i . m a r i a @ u k s w . e d u, ~}{ }^{3}$ chris.rudianto@uksw.edu \\ Email Penulis Korespondensi: evi.maria@uksw.edu \\ Submitted: 16/12/2021; Accepted: 26/12/2021; Published: 31/12/2021
}

\begin{abstract}
Abstrak-Tujuan riset ini adalah merancang sistem informasi persediaan barang di Balai Latihan Kerja, Kota Salatiga. Riset ini fokus merancang sistem mulai proses pengajuan dan persetujuan anggaran, transaksi barang masuk dan keluar, serta pencatatan dan pelaporan barang. Pengembangan sistem informasi dalam riset ini menggunakan metode prototype dengan framework bootstrap dan basis data MySQL. Hasil riset ini adalah desain sistem informasi persediaan barang untuk diimplementasikan di Balai Latihan Kerja, Kota Salatiga. Hasil pengujuan menunjukkan bahwa desain sistem informasi persediaan barang yang dihasilkan riset ini dapat menghasilkan laporan persediaan barang yang akurat dan tepat waktu serta bebas dari eror. Hasil riset diharapkan dapat menjadi solusi masalah pengelolaan barang terkait akurasi dan ketepat waktuan penyajian laporan persediaan disana.
\end{abstract}

Kata Kunci: Sistem Informasi; Persediaan; Sistem Informasi Persediaan; Framework Bootstrap; Model Prototype

\begin{abstract}
The purpose of this research is to design an inventory information system at the Work Training Hall, Salatiga City. This research focuses on designing the system of starting the process of filing and approval of budgets, transactions of goods in and out, and recording and reporting of goods. The development of information systems in this research uses prototype methods with bootstrap framework and MySQL database. The result of this research is the design of the inventory information system to be implemented at the Work Training Hall, Salatiga City. The results showed that the design of the inventory information system produced by this research can produce accurate and timely inventory reports and free from errors. The results of the research are expected to be a solution to the problem of managing goods related to the accuracy and timely presentation of inventory reports there.
\end{abstract}

Keywords: Information System; Inventory; Inventory Information System; Bootstrap Framework; Prototype Model

\section{PENDAHULUAN}

Persediaan barang dalam sebuah organisasi memegang peranan penting. Persediaan barang yang banyak jenisnya dengan tingkat perputaran barang yang cukup tinggi perlu dikelola dengan baik. Pengelolaan yang baik dapat mencegah dan mengurangi masalah-masalah kerusakan barang karena terlalu lama disimpan di gudang, kelebihan barang, kekurangan barang dan/atau kehabisan barang. Jika kondisi ini dibiarkan maka akan menganggu kegiatan operasional dan pelayanan dari perusahaan. Oleh sebab itu, pengelolaan barang secara manual sudah tidak lagi cocok digunakan saat ini. Pengelolaan secara manual banyak kali memunculkan masalah, seperti tidak diketahui jumlah stok barang di gudang, ketidakakuratan laporan stok barang yang dihasilkan, proses pencarian data dan barang yang lama [1] membuat perusahaan memerlukan bantuan teknologi informasi untuk membantu mengelola persediaannya. Penerapan teknologi informasi diharapkan dapat menjadi solusi dari masalah-masalah pengelolaan persediaan barang di perusahaan. Ini artinya, riset tentang penerapan teknologi informasi untuk mengelola persediaan barang di perusahaan masih menarik diteliti.

Masalah pengelolaan persediaan barang juga dialami oleh Balai Latihan Kerja, Kota Salatiga. Balai ini merupakan salah satu bagian dalam Dinas Perindustrian dan Tenaga Kerja (Disperinnaker), Kota Salatiga. Menurut informasi yang diperoleh saat wawancara dan observasi selama praktik kerja, meskipun Disperinnaker sudah menggunakan teknologi informasi dan internet dalam kegiatan operasional dan pelayanan publik, namun pengelolaan persediaan barang disana masih dilakukan secara manual. Pencatatan persediaan barang disana masih dilakukan pada buku, kemudian setiap minggu akan diinput ke Microsoft Excel. Pencatatan seperti ini, membutuhkan waktu cukup lama untuk menghasilkan laporan barang disana. Informasi terkait stok barang tidak bisa disajikan tepat waktu, sehingga seringkali barang tidak tersedia saat Balai Latihan Kerja akan melaksanakan kegiatan. Tak hanya itu, Disperinnaker juga seringkali memiliki stok barang tertentu yang sangat banyak, sehingga membutuhkan tempat untuk penyimpanan barang yang besar untuk menampung barang-barang tersebut. Pendataan persediaan barang secara manual tersebut, kurang efektif karena laporan dan data yang dihasilkan bisa jadi tidak akurat, Kondisi ini membuat Balai Latihan Kerja, Kota Salatiga perlu untuk membangun sistem informasi persedian barang berbasis website untuk memudahkan pengelolaan dan pelaporan persediaan barang disana.

Riset di sekolah [2], universitas [3], toko dan online shop fashion [4][5][6], perusahaan dagang berbentuk Perseroan Terbatas [1][7][8][9] telah mencoba membuat rancangan tentang sistem informasi persediaan barang. Namun, adanya perbedaan karakteristik usaha dan standar akuntansi membuat desain dari sistem persediaan barang yang sudah dihasilkan dalam riset-riset terdahulu tidak bisa langsung diimplementasikan di Balai Latihan Kerja, Kota Salatiga. Instansi pemerintah menggunakan Standar Akuntansi pemerintah (SAP) yang diterbitkan oleh Komite Standar Akuntansi Pemerintahan [10] untuk mengatur pelaporan dan pencatatan persediaan barang yang dimilikinya. Ini berbeda dengan perusahaan yang melaporkan dan mencatat persediaan barangnya menggunakan Standar 
Akuntansi Keuangan (SAK). Ini membuat, riset untuk merancang sistem informasi persediaan barang di Balai Latihan Kerja, Kota Salatiga masih perlu dilakukan.

Dari masalah pengelolaan dan pelaporan transakaksi persediaan barang, maka riset ini memilih untuk mengembangan sistem informasi persediaan barang menggunakan metode prototype. Bagan desain sistem dibuat dalam bentuk flowchart, use case diagram dan entity relationship diagram serta aplikasi berbasis website yang dibangun menggunakan basis data MySQL. Riset ini menggunakan framework bootstrap untuk pengembangan aplikasinya karena framework ini dapat menghasilkan tampilan website yang responsif [11][12]. Tampilan website yang dihasilkan akan menyesuaikan ukuran layar dari browser yang akan digunakan. Jadi, tampilan website yang dihasilkan nanti, tidak akan tergangu oleh resolusi layar. Framework ini juga menyediakan library yang berisi bermacam-macam script yang bisa langsung digunakan atau dimodifikasi sesuai dengan kebutuhan. Ini membantu para pengembang aplikasi dapat lebih fleksibel dan hemat waktu dalam mengembangkan aplikasi. Oleh sebab itu, riset ini dilakukan dengan tujuan untuk membuat desain sistem informasi persediaan barang berbasis website di Balai Latihan Kerja, Kota Salatiga.

Ada dua kontribusi riset ini. Pertama, riset berkontribusi untuk pengembangan ilmu bidang sistem informasi, karena hasil riset membuktikan bahwa penerapan sistem informasi berbasis website mampu membuat penyajian laporan barang dalam sebuah organisasi dapat disajikan tepat waktu dan akurat. Kedua, berkontribusi bagi Disperinnaker, Salatiga. Hasil riset ini memberikan rekomendasi atas masalah pengelolaan persediaan barang pada dinas, mulai dari permintaan dan persetujuan anggaran, barang masuk dan keluar serta pencatatan dan pelaporan persediaan barang. Penerapan sistem ini, diharapkan dapat membantu dinas untuk bisa lebih transparan dan akuntabel dalam pengelolaan persediaan barang disana serta penyajian laporan persediaan barang dapat lebih tepat waktu.

\section{METODOLOGI PENELITIAN}

\subsection{Tahapan Penelitian}

Model prototype digunakan dalam pengembangan sistem informasi dalam riset ini. Metode ini menawarkan pendekatan yang lebih baik, karena memperhatikan kebutuhan rinci terkait fungsi dan fitur yang dari pengguna ketika akan mengembangkan perangkat lunak [13][14]. Tahapan model prototype ada empat, seperti yang disajikan pada Gambar 1. Pertama, tahap identifikasi kebutuhan. Dalam tahap ini, dilakukan pengumpulan data tentang proses bisnis dari sistem persediaan yang sedang berjalan di Balai Latihan Kerja, Disperinnaker Salatiga, sehingga dapat dilakukan analisis kelebihan dan kelemahan sistem. Proses bisnis disana ditampilkan menggunakan flowchart. Tujuannya, untuk memudahakan proses analisis. Kedua, tahap merancang sistem. Dalam tahap ini ada berbagai aktivitas yang dilakukan, seperti membangun prototype, evaluasi prototype, coding sistem dan evaluasi sistem. Pada bagian ini akan disusun user case diagram dan entity relationship diagram, perancangan tabel, form, dan report. Ketiga, tahap implementasi sistem, yaitu tahap dimana semua rancangan diimplementasikan pada aplikasi mulai dari tabel, form, dan report. Keempat, tahap pengujian sistem. Tujuannya, untuk mengetahui apakah aplikasi yang diimplementasikan sudah berjalan sesuai dengan fungsinya.

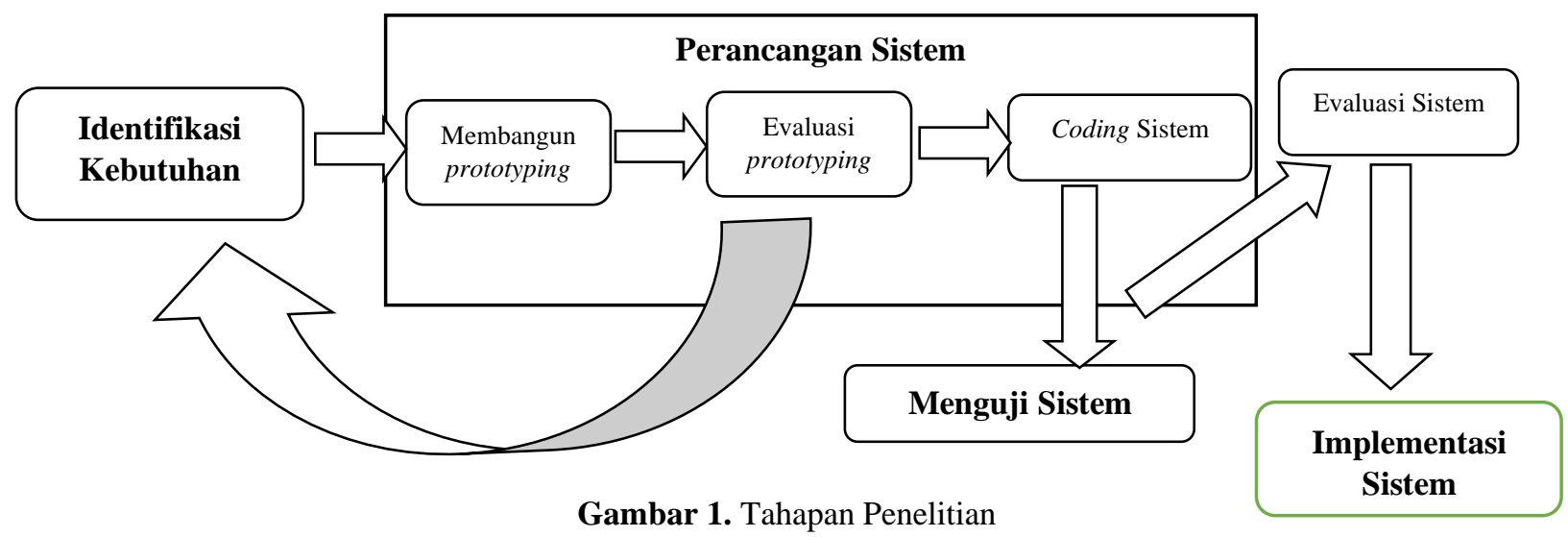

\subsection{Pendekatan dan Metode Pengumpulan Data}

Riset ini menggunakan pendekatan Research and Development (R\&D) karena menciptakan produk baru berupa sistem informasi persediaan barang untuk Balai Latihan Kerja, Dinas Perindustrian dan Tenaga Kerja (Disperinnaker), Salatiga berbasis website. Data primer dan data sekunder digunakan dalam riset ini. Data primer berupa siklus persediaan di dinas tersebut, diperoleh dari hasil observasi dan wawancara dengan pihak-pihak yang terkait dalam sistem. Daftar pertanyaan terkait sistem informasi persediaan digunakan sebagai panduan dalam wawancara. Data sekunder dipeoleh dari proses pemeriksaan dokumen dan catatan yang digunakan dalam siklus persediaan barang disana. 
Framework bootstrap dipilih digunakan untuk mengembangkan sistem persediaan barang di Balai Latihan Kerja, Kota Salatiga. Framework ini dipilih digunakan karena menghemat waktu dalam proses pembuatan front end website karena tersedia library yang isinya script yang sudah siap untuk dipakai [12][15]. Penggunaan framework ini menguntungkan pengembang sistem karena script yang ada bisa dimodifikasi sesuai dengan kebutuhan, sehingga membuat pekerjaan pengembangan sistem menjadi lebih fleksibel dan hemat waktu [11][12]. Kondisi ini tentu berdampak pada biaya pengembangan sistem dengan framework ini juga tidak mahal [16]. MySQL digunakan sebagai database dalam riset ini.

\section{HASIL DAN PEMBAHASAN}

\subsection{Analisis Kebutuhan}

Hasil observasi dan wawancara pada sistem informasi persediaan barang di Balai Latihan Kerja, Kota Salatiga dapat diidentifikasi kelebihan dan kelemahan sistem. Balai Latihan Kerja sudah memiliki prosedur yang memadai dalam upaya memenuhi kebutuhan informasi terkait persediaan barang yang biasa digunakan untuk kegiatan pelatihan kerja disana. Adapun alur proses pencatatan barang yang sedang berjalan disana saat ini disajikan menggunakan flowchart di Gambar 2.
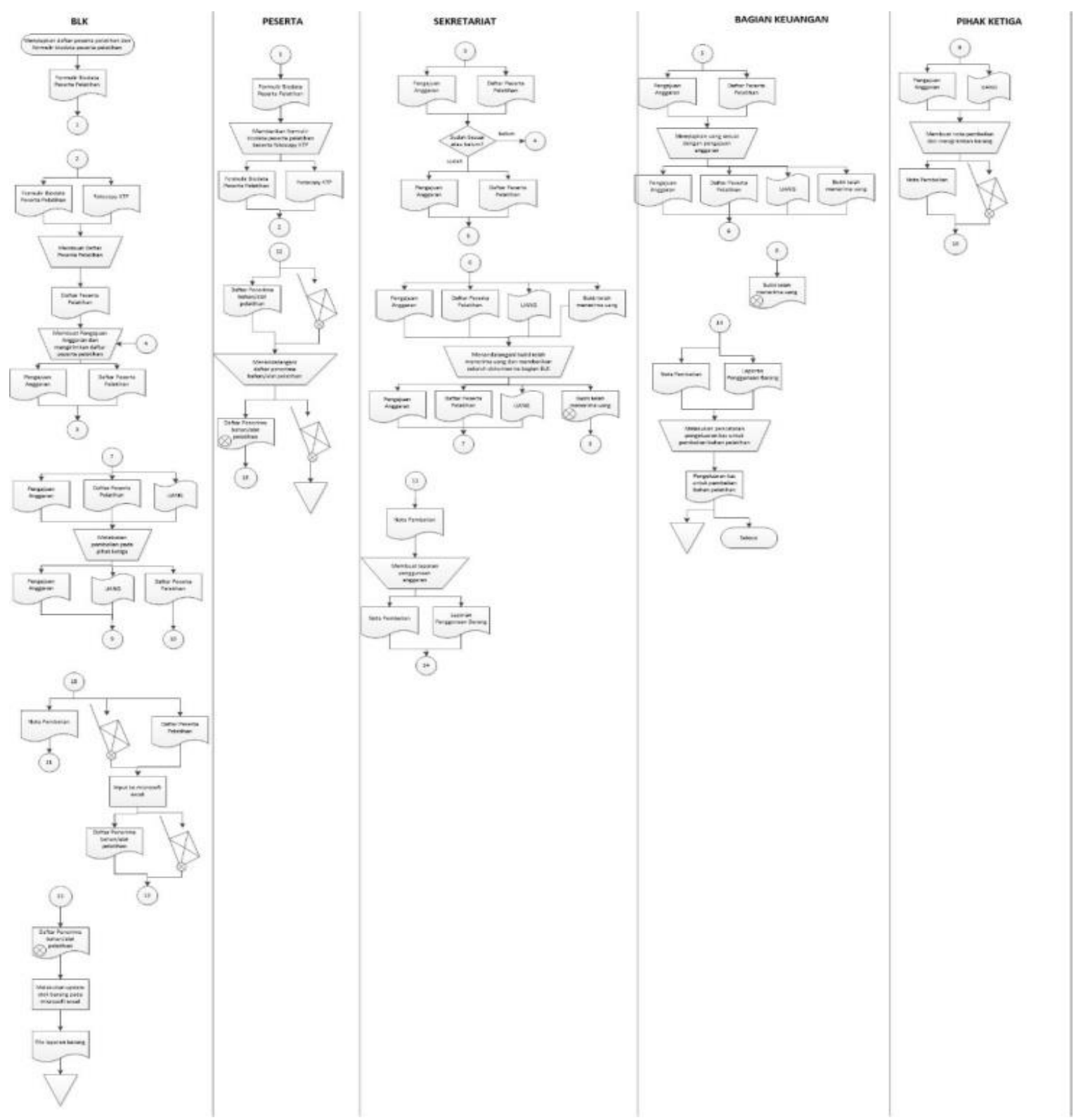

Gambar 2. Flowchart Prosedur Persediaan Barang di Balai Latihan Kerja, Kota Salatiga

Dari prosedur tersebut, diketahui kelemahan sistem persediaan barang di sana. Dinas membutuhkan waktu yang lama ketika akan menyajikan laporan persediaan barang. Penyebabnya, pencatatan keluar masuknya barang disana, masih dilakukan secara manual dengan ditulis tangan pada buku catatan dan/atau menggunakan bantuan 
aplikasi Microsoft Excel. Pencatatan secara manual tidak hanya menyebabkan keterlambatan penyajian laporan persediaan tetapi juga membutuhkan waktu yang lama ketika akan mengetahui jumlah persediaan barang untuk kegiatan pelatihan disana. Ini karena bagian latihan kerja haruse mengecek lembar per lembar untuk mencari barang yanag dicari. Pencatatan secara manual mengandalkan perhitungan barang menggunakan kalkulator dan/atau perhitungan antar sheet di Microsoft Excel juga menimbulkan masalah pada akurasi perhitungan barang.

Kelemahan sistem persediaan yang sedang berjalan pada dinas tersebut, mendorong dinas perlu untuk mengembangkan sistem informasi persediaan berbasis website. Aplikasi in dharapkan dapat memudahkan dinas untuk mengelola persediaan barang untuk digunakan dalam kegiatan pelatihan kerja disana. Pengelolaan persediaan barang yang transparan dan akuntabel, diharapkan dapat memberi dampak pada peningkatan kinerja dari dinas dalam rangka mendukung kegiatan layanan publik disana.

Adapun kebutuhan agar sistem informasi persediaan barang berbasis website dapat berjalan disana, antara lain perangkat keras dan perangkat lunak dengan spesifikasi minimum tertentu. Processor Standart Dual Core, memori minimal $2 \mathrm{~GB}$, dan harddisk dengan kapasitas minimal $500 \mathrm{~GB}$ adalah daftar perangkat keras yang dibutuhkan untuk menjalankan aplikasi ini. Sedangkan, MySQL dan WEB Browser, server menggunakan Xampp/Wampp, dan sistem operasi minimal Windows 7 adalah daftar perangkat lunak yang dibutuhkan.

\subsection{Perancangan Sistem}

Riset memodelkan desain sistem informasi persediaan di Balai Latihan Kerja, Kota Salatiga menggunakan tiga diagram. Pertama, desain use case diagram sistem informasi persediaan, seperti disajikan pada Gambar 3. Aktor yang terlibat dalam sistem dan interaksinya dijelaskan menggunakan diagram tersebut [17]. Ada dua aktor yang terlibat. Pertama, Bagian Pengurus Barang Pengguna berperan sebagai pemberi informasi terkait barang-barang yang dimiliki oleh dinas yang dapat digunakan dalam aktivitas pelatihan kerja disana. Kedua, Bagian Keuangan berperan dalam proses persetujuan dan pembayaran pengadaan barang disana.

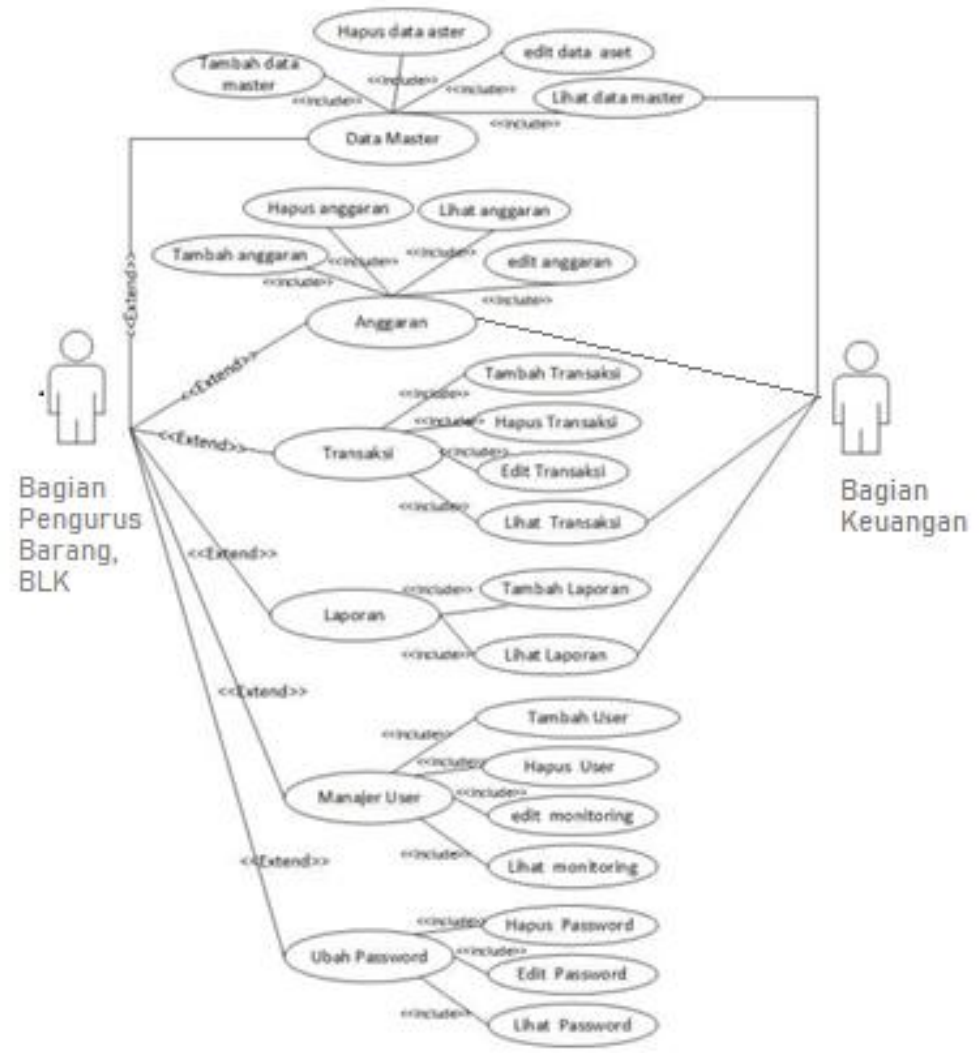

Gambar 3. Use Case Diagram Sistem Informasi Persediaan Barang di Balai Latihan Kerja, Kota Salatiga

Kedua, desain Entity Relationship Diagram (ERD) sistem informasi persediaan barang di Balai Latihan Kerja, Kota Salatiga. Diagram ini berfungsi menggambarlam struktur sistem informasi persediaan barang di rancang untuk Balai Latihan Kerja, Kota Salatiga. Entitas sistem informasi persediaan yang dijelaskan, antara lain barang masuk, barang keluar, users, barang, jenis barang, dan satuan. 


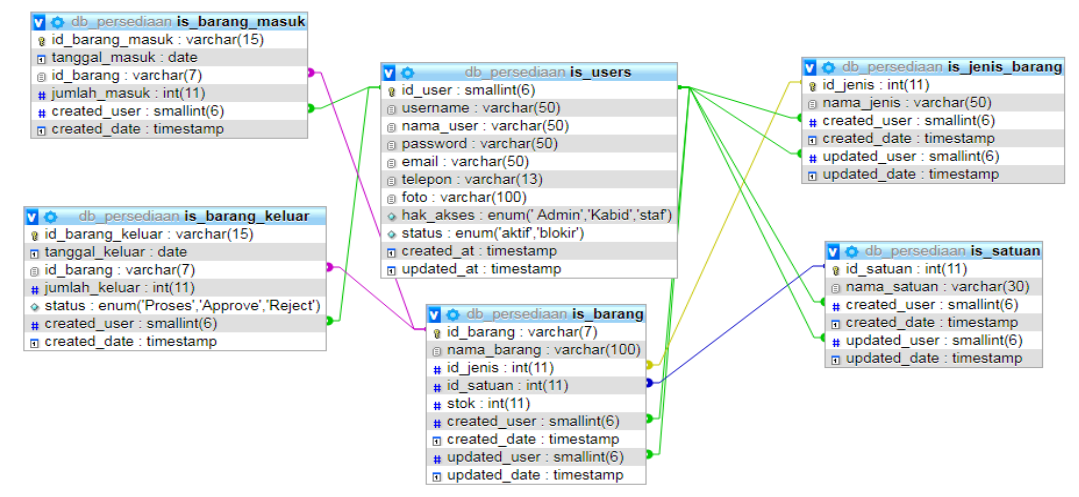

Gambar 4. Entity Relationship Diagram Sistem Informasi Persediaan Barang di Balai Latihan Kerja, Salatiga

\subsection{Implementasi Sistem}

Kode program diterjemahkan dalam bentuk user interface di tahap implementasi sistem ini. Rancangan sistem informasi persediaan barang yang sudah dibuat padai tahap sebelumnya, diimplementasikan di tahap ini. Implementasi sistem informasi persediaan barang di Balai Latihan Kerja, Kota Salatiga dijelaskan berikut ini.

1. Implementasi laman login pada aplikasi persediaan barang di Balai Latihan Kerja, Kota Salatiga. Pengguna wajib untuk melakukan login agar dapat mengakses aplikasi. Login dilakukan dengan cara memasukkan username dan password, lalu klik tombol login. Gambar 5 menyajikan tampilan laman login dari aplikasi persediaan barang.

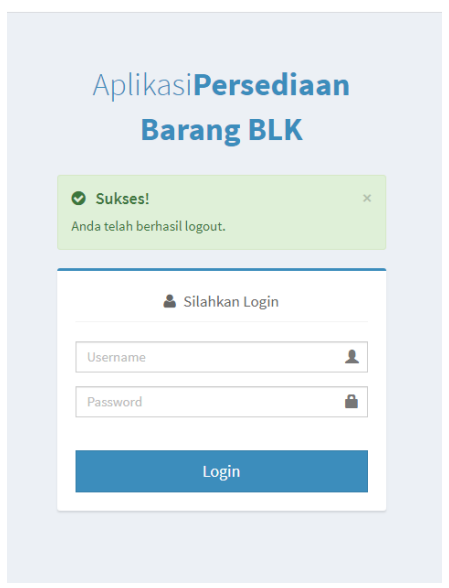

Gambar 5. Laman Login pada Aplikasi Persediaan Barang di Balai Latihan Kerja, Kota Salatiga

2. Implementasi laman beranda dalam aplikasi persediaan barang di Balai Latihan Kerja, Kota Salatiga. Fungsi laman ini adalah menampung seluruh menu yang ada di aplikasi persediaan barang di Balai Latihan Kerja, Salatiga. Gambar 6 menyajikan tampilam laman Beranda aplikasi persediaan barang. Di laman Beranda, aplikasi ini dilengkapi dengan menu utama, seperti data barang, barang masuk, barang keluar dan user. Pada laman beranda ini juga terdapat lima menu lainnya, yaitu menu data master, menu anggaran, menu transaksi, menu laporan dan menu manajemen user. Pada laman ini juga, ada user di sebelah kanan atas, jika tombol tersebut di klik, maka muncul tombol logout dan edit profil. Jika tombol edit profil di klik, maka aplikasi akan masuk secara otomatis ke menu manajemen user.

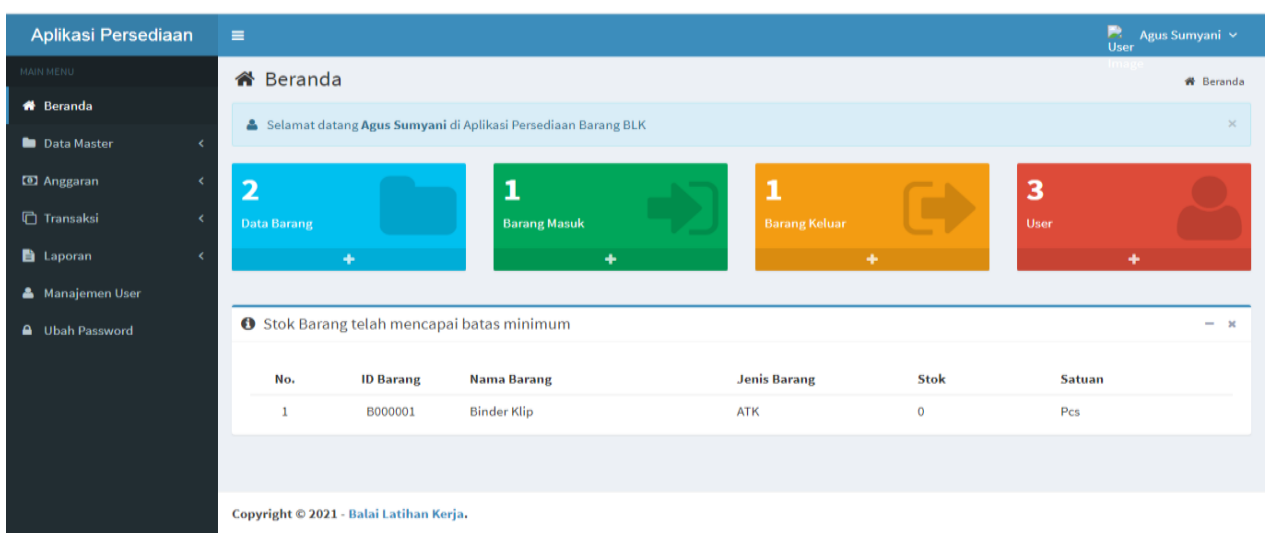

Gambar 6. Laman Beranda pada Aplikasi Persediaan Barang di Balai Latihan Kerja, Kota Salatiga 
Building of Informatics, Technology and Science (BITS)

Volume 3, No 3, December 2021, Page 194-202

ISSN 2684-8910 (media cetak)

ISSN 2685-3310 (media online)

DOI 10.47065/bits.v3i3.1043

3. Implementasi laman menu data master dalam dalam aplikasi persediaan barang di Balai Latihan Kerja, Kota Salatiga. Data master terdiri dari sub menu data barang, jenis barang dan satuan. Tampilan menu Data Master disajikan pada Gambar 7. Menu ini digunakan untuk menampilkan daftar barang yang sudah diklasifikasikan berdasarkan jenis penggunaan barang tersebut, apakah untuk kegiatan pelatihan, percetakan atau alat tulis kantor. Menu ini juga menyediakan tombol tambah data barang, ubah dengan simbol pensil dan hapus dengan simbol tong sampah serta tersedia field cari untuk memudahkan user ketika akan mencari data persediaan barang milik dinas.

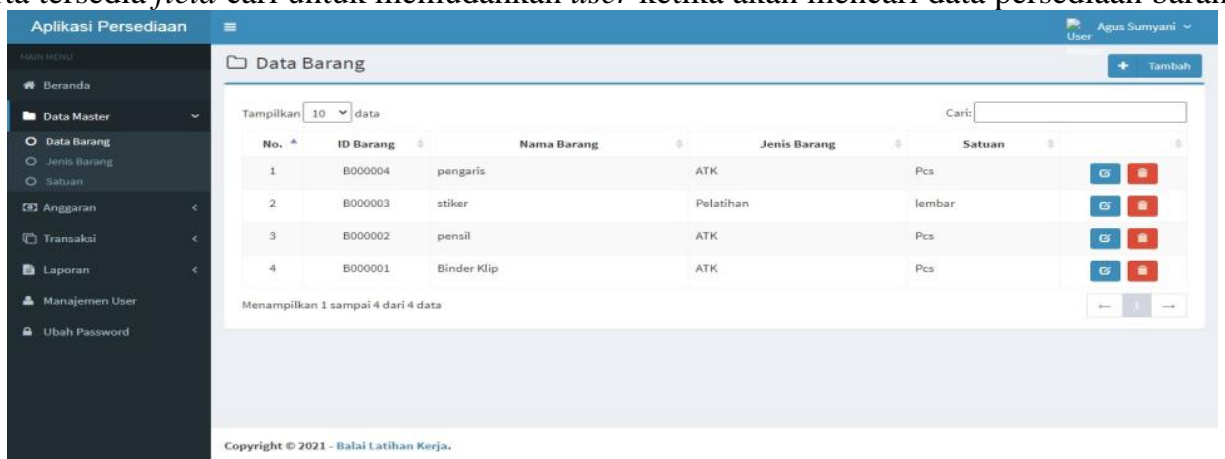

Gambar 7. Menu Data Master pada Aplikasi Persediaan Barang di Balai Latihan Kerja, Kota Salatiga

4. Implementasi laman menu anggaran dalam aplikasi persediaan barang di Balai Latihan Kerja, Kota Salatiga. Menu anggaran terdiri dari create anggaran dan verifikasi anggaran. Tampilan menu Anggaran disajikan pada Gambar 8. Pada menu ini tersedia sub menu create anggaran, yaitu menu yang berfungsi untuk membuat usulan pengajuan anggaran untuk pengadaan barang disana. Selain itu, menu ini juga dapat menampilkan daftar pengajuan anggaran, yang berisi ID anggaran, tanggal pengajuan anggaran, nama barang, nilai pengajuan untuk pengadaan barang dan status. Pada laman ini, tidak disediakan tombol edit dan hapus pengajuan anggaran untuk tujuan keamanan. User hanya boleh melakukan tambah data. Pada laman ini, tersedia field cari untuk memudahkan user ketika akan mencari status pengajuan anggaran apakah pengajuan diterima atau ditolak.

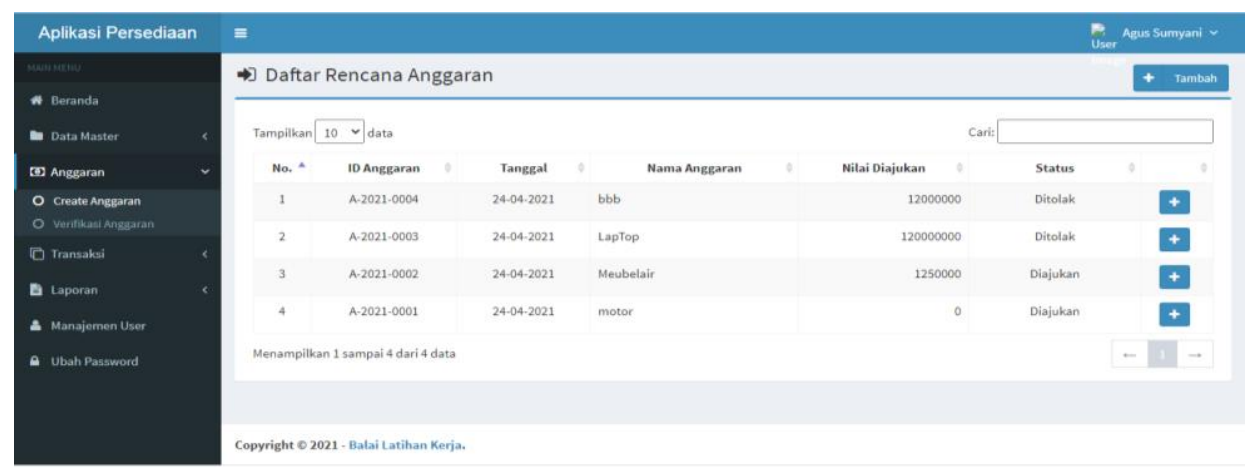

Gambar 8. Menu Anggaran pada Aplikasi Persediaan Barang di Balai Latihan Kerja, Kota Salatiga

5. Implementasi laman menu transaksi dalam aplikasi persediaan barang di Balai Latihan Kerja, Kota Salatiga. Menu transaksi terdiri dari barang masuk dan barang keluar. Laman transaksi barang masuk berfungsi untuk menginput data penerimaan barang dari transaksi pembelian dan transaksi pengembalian barang dari user. Laman ini memiliki tombol simpan jika input transaksi sudah benar dan tombol batal jika transaksi tidak jadi dilakukan penginputan. Laman transaksi barang masuk disajikan pada Gambar 9. Sedangkan laman transaksi barang keluar untuk input data pengeluaran barang dari gudang, mudal dari ID transaksi, tanggal transaksi, ID barang, nama barang, jumlah barang keluar dan status pengeluaran barang. Laman transaksi barang keluar disajikan pada Gambar 10.

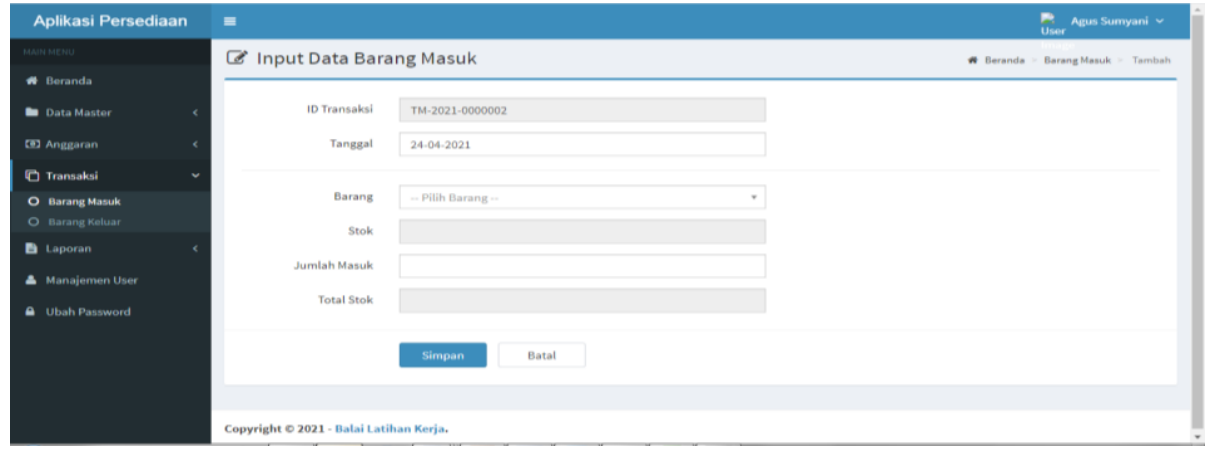

Gambar 9. Menu Input Barang Masuk pada Aplikasi Persediaan Barang di Balai Latihan Kerja, Salatiga 


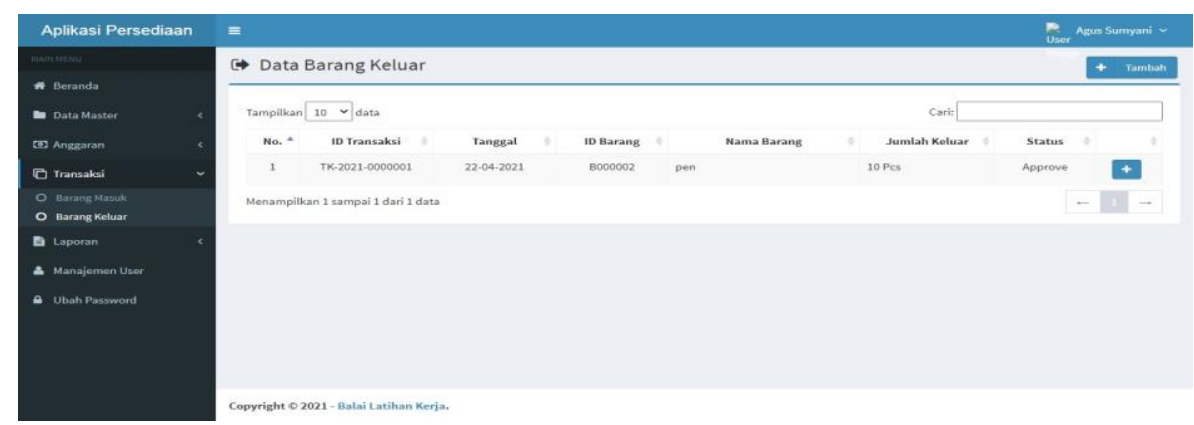

Gambar 10. Menu Data Barang Keluar pada Aplikasi Persediaan Barang di Balai Latihan Kerja, Salatiga

6. Implementasi laman menu laporan dalam aplikasi persediaan barang di Balai Latihan Kerja, Kota Salatiga. Menu ini terdiri dari laporan stok barang, laporan barang masuk dan laporan barang keluar. Laman menu laporan stok barang berfungsi untuk menginformasikan daftar barang, jenis dan banyaknya stok yang dimiliki oleh Balai Latihan Kerja, seperti yang tersaji pada Gambar 11. Sedangkan laporan barang masuk seperti yang tersaji pada Gambar 12 dan laporan barang keluar berisi daftar barang masuk dan keluar pada Balai Latihan Kerja pada suatu periode tertentu. Seluruh laporan yang dihasilkan dari aplikasi ini dapat di cetak.

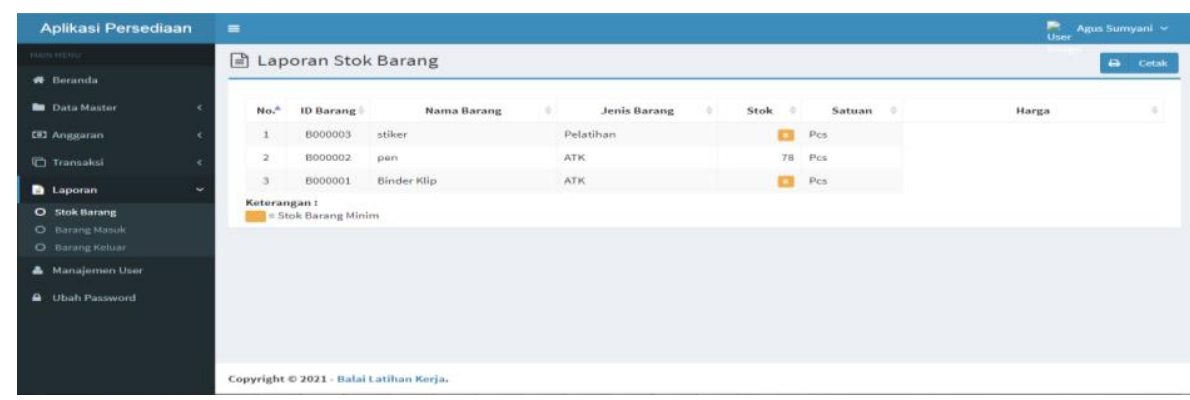

Gambar 11. Menu Laporan Stok Barang pada Aplikasi Persediaan Barang di Balai Latihan Kerja, Salatiga
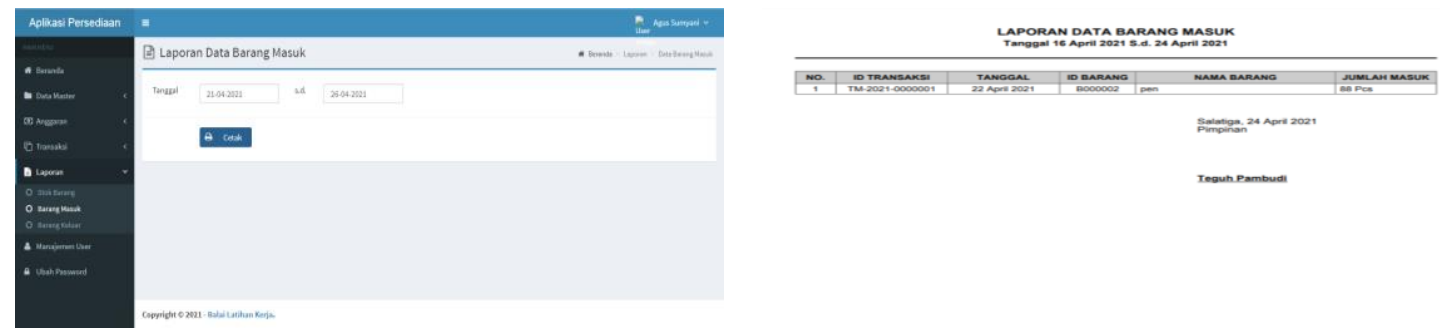

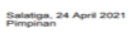

Gambar 12. Menu Laporan Data Barang Masuk dan Hasil Cetaknya

7. Implementasi laman manajemen user dalam aplikasi persediaan barang di Balai Latihan Kerja, Kota Salatiga. Laman ini berfungsi untuk melihat siapa saja user yang memiliki hak akses dari aplikasi ini dan juga menambah, mengedit, atau memblokir akses dari user. Laman manajemen user dapat di lihat pada Gambar 13. Dalam menu ini, ada informasi user antara lain foto, username, nama user, hak akses, dan status. Di menu ini juga tersedia tiga tombol, yaitu tombol untuk memblokir, mengedit dan menambah user. Di menu ini juga, tersedia field cari untuk memudahkan mencari data terkait user yang memiliki hak akses dalam aplikasi ini.

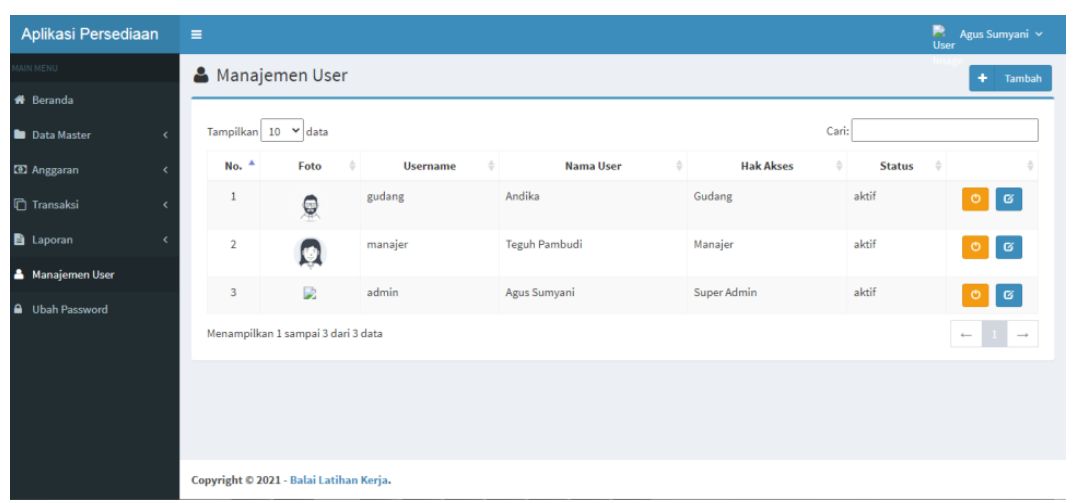

Gambar 13. Menu Manajemen User pada Aplikasi Persediaan Barang di Balai Latihan Kerja, Salatiga 


\subsection{Pengujian Sistem}

Tahap ini adalah tahap terakhir dari proses pengembangan sistem informasi persediaan barang di Balai Latihan Kerja, Kota Salatiga, yaitu pengujian sistem. Tujuannya adalah untuk memastikan bahwa aplikasi yang dihasilkan telah berjalan sesuai dengan fungsinya dan tujuan pembuatannya. Hasil pengujian disajikan pada Tabel 1 dan Tabel 2. Hasil pengujian menunjukkan bahwa tombol yang ada dalam aplikasi ini sudah bekerja dengan baik dan sesuai dengan desain yang telah dibuat. Selain itu, hasil pengujian kecepatan dan ketepatan hasil menunjukkan bahwa aplikasi lebih cepat dan tepat dalam menghasilkan laporan persediaan barang dibandingkan dengan sistem lama, yaitu pencatatan secara manual. Aplikasi berguna untuk mendukung seluruh aktivitas yang terjadi pada siklus persediaan barang di Balai Latihan Kerja, Kota Salatiga.

Tabel 1. Hasil Pengujian Sistem

\begin{tabular}{lllll}
\hline No & \multicolumn{1}{c}{ Materi Uji } & \multicolumn{1}{c}{ Harapan Uji } & \multicolumn{1}{c}{ Hasil Uji } & Keterangan \\
\hline 1. & Laman login & Menampilkan laman login & Laman login tampil & Berhasil \\
2. & Laman beranda & Menampilkan laman beranda & Laman beranda tampil & Berhasil \\
3. & Tambah data & Tombol tambah data berfungsi & Tombol tambah berfugsi & Berhasil \\
4. & Edit data & Tombol edit data berfungsi & Tombol edit data berfugsi & Berhasil \\
5. & Hapus data & Tombol hapus data berfungsi & Tombol hapus data berfugsi & Berhasil \\
6. & Simpan data & Tombol simpan data berfugsi & Tombol simpan data berfugsi & Berhasil \\
7. & Kembali & Tombol kembali berfugsi & Tombol kembali berfugsi & Berhasil \\
8. & Cetak data & Tombol cetak berfugsi & Tombol cetak berfugsi & Berhasil \\
9 & Pencarian data & Tombol cari data berfugsi & Tombol cari berfugsi & Berhasil \\
\hline
\end{tabular}
Sumber: data primer diolah

Tabel 2. Hasil Pengujian Kecepatan dan Ketepatan Sistem

\begin{tabular}{lrrrr}
\hline Kondisi pengujian & \multicolumn{2}{c}{ Ketepatan } & \multicolumn{2}{c}{ Kecepatan } \\
\cline { 2 - 5 } & Aplikasi & Manual & Aplikasi & \multicolumn{1}{c}{ Manual } \\
\hline Input barang masuk 3 data & $100 \%$ & $80 \%$ & 6 menit & 15 menit \\
Pembuatan laporan & $100 \%$ & $75 \%$ & 15 menit & 45 menit \\
Cetak laporan & $100 \%$ & $80 \%$ & 1 menit & 5 menit \\
\hline
\end{tabular}

Sumber: data primer diolah

\section{KESIMPULAN}

Riset ini menyediakan desain sistem informasi persediaan barang di Balai Latihan Kerja, Kota Salatiga. Riset ini fokus merancang sistem mulai dari pendataan barang baik barang masuk dan keluar, pengadaan dan persetujuannya, serta pembuatan laporan barang. Riset ini menghasilkan desain sistem informasi persediaan barang khusus untuk diimplementasikan pada Balai Latihan Kerja di Dinas Perindustrian dan Tenaga Kerja, Kota Salatiga. Sistem informasi ini diharapkan dapat menjadi solusi atas masalah keterlambatan dan ketidak akuratan pencatatan persediaan barang di instansi tersebut. Namun demikian, sistem informasi yang dibangun ini belum terintegrasi dengan sistem informasi keuangan di dinas, meski lingkup sistem ini juga termasuk pengajuaan penggunaan anggaran untuk pendanaan pengadaan barang di instansi tersebut. Oleh sebab itu, riset ke depan diharapkan dapat mengintegrasikan sistem informasi persediaan barang ini dengan sistem informasi keuangan sehingga dapat digunakan untuk memproses pembayaran kegiatan pengadaan barang disana.

\section{REFERENCES}

[1] M. M. Purba and C. Rahmat, "Perancangan Sistem Informasi Stok Barang Berbasis Web di PT. Mahesa Cipta," JSI (Jurnal Sist. Informasi) Univ. Suryadarma, vol. 8, no. 2, pp. 123-158, 2021, [Online]. Available: https://doi.org/10.1101/2020.11.10.376129.

[2] A. S. Wati, E. Maria, and A. D. Cahyono, "Otomatisasi Sistem Inventarisasi Barang di Sekolah: Studi pada SD Negeri Sidorejo Lor 06, Salatiga,” Aiti, vol. 17, no. 1, pp. 56-71, 2020, doi: 10.24246/aiti.v17i1.56-71.

[3] S. Munawaroh, "Perancangan Sistem Informasi Persediaan Barang," J. Teknol. Inf. Din., vol. XI, no. 2, pp. 124-133, 2006.

[4] M. Samsudin, M. Service, D. F. Diagram, and R. Diagram, "Analisa Dan Perancangan Sistem Informasi Persediaan Barang Pada Bali Creative Silver Berbasis Web Dan SMS Gateway," no. 86.

[5] E. Najwaini, P. Purnama, and N. Rizki Aulia, "Perancangan Sistem Informasi Persediaan Barang Berbasis Web pada Alzena Hijab Store Banjarmasin,” J. Ilmu Komput. dan Bisnis, vol. 11, no. 2, pp. 2473-2482, 2020, doi: 10.47927/jikb.v11i2.225.

[6] S. Bakhri, "Rancang Bangun Sistem Informasi Penjualan Sembako Menggunakan Model Waterfall," J. Khatulistiwa Inform., vol. 1, pp. 1-17, 2015, doi: https://doi.org/10.1145/3132847.3132886.

[7] M. Mulyadi and M. Nandi Susila, "Sistem Informasi Persediaan Barang Berbasis Web Pada PT. Wirausaha Muda Mandiri Jakarta,” Smart Comp Jurnalnya Orang Pint. Komput., vol. 10, no. 1, pp. 35-39, 2021, doi: 10.30591/smartcomp.v10i1.2212.

[8] M. Rosmiati, "Aplikasi Persediaan Sparepart Mesin Berbasis Web Pada PT Giesecke and Devrient Indonesia,” J. Tek. Komput., vol. 2, pp. 119-124, 2018, doi: https://doi.org/10.31294/jtk.v4i2.3686. 
Building of Informatics, Technology and Science (BITS)

Volume 3, No 3, December 2021, Page 194-202

ISSN 2684-8910 (media cetak)

ISSN 2685-3310 (media online)

DOI 10.47065/bits.v3i3.1043

[9] A. Sidik, E. T. B. Waluyo, and S. Susilawati, "Perancangan Sistem Informasi Laporan Persediaan Barang Jadi PT Duta Prima Plasindo," J. Sifotek Glob., vol. 8, no. 1, pp. 7-12, 2018, doi: p://dx.doi.org/10.38101/sisfotek.v8i1.161.

[10] Komite Standar Akuntansi Pemerintahan, Standar Akuntansi Pemerintahan. Indonesia, 2020.

[11] T. J. Riasinir and Widyasari, "Pemanfaatan Framework Bootstrap Dalam Merancang Website Responsif Untuk Toko D2 Adventure," J. Enter, vol. 2, pp. 346-355, 2019.

[12] T. Listyorini and M. Iqbal, "Perancangan Pengembangan Digital Library Berbasis Web Responsif," J. Simetris, vol. 6, no. 1, pp. 69-76, 2015.

[13] M. Khosrow-Pour, Encyclopedia of Information Science and Technology. USA: IGI Global Publishing, 2005.

[14] P. Ogedebe and B. P. Jacob, "Software Prototyping: A Strategy to Use When User Lacks Data Processing Experience," ARPN J. Syst. Softw., vol. 2, no. 6, pp. 219-224, 2012.

[15] R. Meimaharani and D. L. Fithri, "E-Commerce Goody Bag Spunbond Menggunakan QR Code Berbasis Web Responsif," J. Simetris, vol. 5, no. 2, pp. 127-135, 2014.

[16] E. Supriyati and R. Meimaharani, "Sistem Informasi Pengobatan Tradisional Jawa (Petraja) Berbasis Web Responsif," J. Simetris, vol. 4, no. 1, pp. 21-29, 2014.

[17] U. Rusmawan, Teknik Penulisan Tugas Akhir dan Skripsi Pemrograman. Jakarta: Elex Media Komputindo, 2019. 